\title{
A book review; "Rare earth elements in human and environmental health; at the crossroads between toxicity and safety"
}

\author{
Kyung-Taek Rim ${ }^{1}$
}

Received: 4 April 2017 / Accepted: 22 June 2017 / Published Online: 30 September 2017

(C) The Korean Society for Applied Biological Chemistry 2017

\begin{abstract}
It is introduced an outstanding book about an important topic in occupational and environmental sciences i.e., the opportunities and challenges that may be connected with increasing the use and distribution of rare earth elements. These chemically similar elements, comprising the lanthanides, scandium, and yttrium, are involved in a number of essential technological applications, and their effects raise a number of human health issues of relevance to the occupational and environmental sciences. The book that I introduced here, "Rare Earth Elements in Human and Environmental Health; At the Crossroads between Toxicity and Safety" edited by Giovanni Pagano (Pan Stanford Publishing Pte. Ltd., Temasek Boulevard, Singapore) represents a break from that situation. It is essential to increase our knowledge about the environmental fate and biological effects of these technologically important metals in order to prevent unforeseen long-term manmade consequences to human health. This book is likely to become an important resource for scientists, engineers, and decision makers who understand the need for sensible exploitation of this resource.
\end{abstract}

Keywords Book review $\cdot$ Crossroad $\cdot$ Rare earths $\cdot$ Safety $\cdot$ Toxicity

Kyung-Taek Rim $(\bowtie)$

E-mail:rim3249@gmail.com

${ }^{1}$ Chemicals Research Bureau, Occupational Safety and Health Research Institute, Korea Occupational Safety and Health Agency, Daejeon, Republic of Korea

This is an Open Access article distributed under the terms of the Creative Commons Attribution Non-Commercial License (http://creativecommons. org/licenses/by-nc/3.0/) which permits unrestricted non-commercial use, distribution, and reproduction in any medium, provided the original work is properly cited.

\section{Introduction}

Peer-reviewed literature about rare earth elements (REEs) has mainly been restricted to developing technologies related to these elements, REE-related chemistry, mineralogy, and economy (Atwood 2012). Recent results about REE-associated health effects have generally been categorized as subtopics or isolated chapters covered as part of these broad topics (US EPA 2012; Izyumov and Plaksin 2013). In addition, REE-associated health effects have been highlighted in a report by the European Agency for Safety and Health at Work in 2013 (EU-OSHA 2013). Although it is clear that studies about REE-associated health effects have thrived in recent years, thus one may recognize that publications have thus far been confined to journal reports based on individual laboratory studies and with a limited number of review articles (Rim et al. 2013; Pagano et al. 2015a; Pagano et al. 2015b). The book that I introduced here, "Rare Earth Elements in Human and Environmental Health; At the Crossroads between Toxicity and Safety" edited by Giovanni Pagano (Pan Stanford Publishing Pte. Ltd. Penthouse Level, Suntec Tower 3, 8 Temasek Boulevard, Singapore 038988, 2017, 280 pp., Print ISBN: 9789814745000, eBook ISBN: 9789814745017; Fig. 1) represents a break from that situation.

\section{Materials and Methods}

It is an important step forward among the recent developments in the field of REE environmental and human health implications, in presenting the multi-faceted aspects of REEs, including its potential benefits in several applications and possible adverse health effects. As stated in the title, "At the Crossroads between Toxicity and Safety," this book provides novel yet established information with a particular emphasis on occupational and environmental health issues. The authors of the different chapters include renowned scientists from the Americas, Europe, and Asia. 


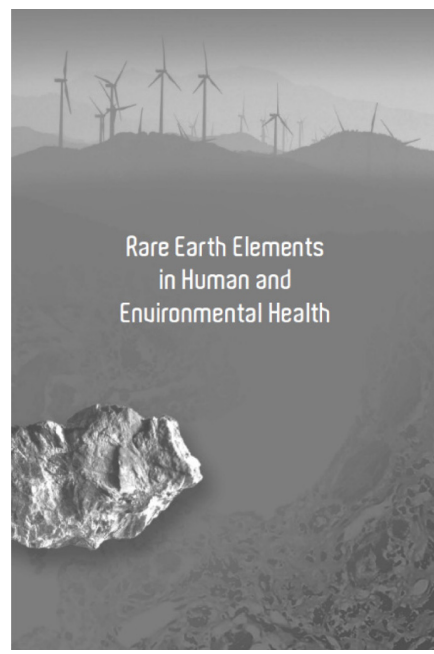

Rare Earth Elements in Human and Enuironmental Health At the crossroads between Toxicity and Safety

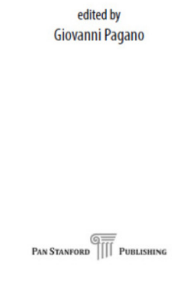

Fig. 1 Front cover of a book for review. Note. From Rare Earth Elements in Human and Environmental Health; At the Crossroads between Toxicity and Safety" edited by Giovanni Pagano. Pan Stanford Publishing Pte. Ltd. Penthouse Level, Suntec Tower 3, 8 Temasek Boulevard, Singapore 038988, Copyright 2017, 280 pp., Print ISBN 9789814745000, eBook ISBN: 9789814745017. Adapted with permission

Each one of these experts has contributed to crucial studies of REE-associated health effects. Authors have in-depth knowledge about a range of environmental and occupational scientific disciplines (Table 1).

\section{Results}

\section{Environmental and occupational issues of REEs}

The book delves into the environmental distribution characteristics of REEs, mechanistic issues, bioaccumulation (in plants, animals, and human beings), and associated pathologies. This two-fold approach in describing REE-related environmental and health issues provides a unique and balanced perspective about REE research and technology. It is also a timely evaluation of the numerous open-ended questions about the health impact of environmental or occupational exposure to REEs that represent ongoing concerns to academia as well as employers and employees in the private sector (Rim et al. 2013).

Researchers can use this book as a valuable tool to gain insight into the complex and sometimes surprising health effects of REEs. The editor of this book has a lot of experience in environmental research and published 105 journal articles and 22 book chapters (Ijad et al. 2017).

I had the privilege to contribute the introductory chapter (Chapter 1) about REE bioaccumulation in humans and associated pathologies. A few reports have shown that REE occupational exposure resulted in bioaccumulation and adverse effects to respiratory tracts (Sabbioni et al. 1982; McDonald et al. 1995; Gong 1996; Yoon et al. 2005). The lack of epidemiological studies about the possible long-term effects of occupational REE exposures represents a major knowledge gap and should remain an outstanding research priority in industrial medicine (Pagano et al. 2015b). Additionally, one may recognize a major role for redox imbalance as a relevant feature of REE-associated toxicity, by reading the mechanistic details provided in Chapter 2 (by Paola Manini). Findings related to excessive production of reactive oxygen species and nitrites (along with the cytogenetic damage that may reflect heritable damage to REE-exposed sperm) have been used to describe REE-associated toxicities (Oral et al. 2010; Pagano et al. 2016). Similar chromosomal aberrations have been found in the bone marrow cells of REE-exposed mice. Collectively, the evidence may also be used to study possible REE-induced clastogenicities and/or genotoxicities in members of other biota (Jha and Singh 1995). Beyond the database of REE-associated adverse effects, it should be noted, however, that antioxidant mechanisms have also been reported to be part of the scope of REE-associated effects, as discussed in Chapter 3 (by Lily L. Wong). In contrast, a separate body of literature has described the beneficial or safe effects of REEs e.g., exertion of antioxidant and neuroprotective actions (Schubert et al. 2006; Pierscionek et al. 2010; Das et al. 2013; Wong and McGinnis 2014). The use of cerium oxide nanoparticles $\left(\mathrm{nCeO}_{2}\right)$ as antioxidants in biological systems has been shown to have a protective effect in terms of reducing oxidative stress in cell culture and in appropriate animal disease models. It has been suggested that the radical-scavenging activities of $\mathrm{nCeO}_{2}$ are mainly due to the increase in the surface area-to-volume ratios in these nanocrystalline structures (Wong and McGinnis 2014). Another study reported that cerium oxide or yttrium oxide nanoparticles protected nerve cells from oxidative stress and that the neuroprotection was independent of the particle size (Schubert et al. 2006). In summary, one can recognize that a line of research has found antioxidant and potentially beneficial effects of REE nanoparticles with potential use in therapeutic applications. REEs have been used for some time in China as additives to animal feed or to improve crops. Beneficial effects that have been reported in the literature include weight gains by different livestock (cattle, pigs, chicken, fish, and rabbits) and increases in food production e.g., more milk and eggs (He et al. 2001; Pang et al. 2002; Redling 2006). However, other studies have extensively investigated REE bioaccumulation and adverse effects to plant growth (Carpenter et al. 2015), algae (Goecke et al. 2015) and other microorganisms (Wen et al. 2011), as discussed in Chapters 4 (by Franca Tommasi and Luigi d'Aquino), 5 (by Luigi d'Aquino and Franca Tommasi), and 6 (by Marco Guida, Antonietta Siciliano, and Giovanni Pagano). In addition to mining and refining activities, worldwide REE manufacturing activities may also raise environmental concerns about REE-polluted wastewater, with consequent bioaccumulation in aquatic biota. Few researchers have investigated this topic (Bustamante and Miramand 2005; Herrmann et al. 2016). The third and most widespread source of REE-related air and soil pollution may refer 
Table 1 The contents of a book for review

\begin{tabular}{ccc}
\hline \hline Contents & Authors of Chapters \\
\hline Preface & Giovanni Pagano
\end{tabular}

Introduction to Rare Earth Elements:

Novel Health Hazards or Safe Technological Devices?

1. Trends in Occupational Toxicology of Rare Earth Elements Kyung-Taek Rim (Occupational Safety and Health Research Institute, Korea Occupational

2. Rare Earth Elements, Oxidative Stress, and Disease

3. Cerium Oxide Nanoparticles-Associated Oxidant and Antioxidant Effects and Mechanisms

4. Rare Earth Elements and Plants

Paola Manini (Department of Chemical Sciences, University of Naples Federico II, Naples, I-80126, Italy)

Lily L. Wong (Department of Ophthalmology, College of Medicine, University of Oklahoma Health Sciences Center (OUHSC) and Dean McGee Eye Institute, Oklahoma City, Oklahoma, USA)

Franca Tommasi (Department of Biology, University of Bari, Bari, Italy) and Luigi d'Aquino (Italian National Agency for New Technologies, Energy and Sustainable Economic Development, Portici Research Center, Italy)

Luigi d'Aquino (Italian National Agency for New Technologies, Energy and Sustainable Economic Development, Portici Research Center, Centro di Ricerche Portici, Piazzale E. Fermi 1, 80055 Portici (NA), Italy) and Franca Tommasi (University of Bari, Department of Biology, Bari, Italy)

Marco Guida (Biology Department, Environmental Hygiene, Federico II Naples

6. Rare Earth Element Toxicity to Marine and Freshwater University, Naples, Italy), Antonietta Siciliano (Department of Chemical Sciences, Algae

Federico II Naples University, Naples, Italy), and Giovanni Pagano (Department of Chemical Sciences, Federico II Naples University, Naples, Italy)

Philippe J. Thomas (Environment Canada, Science \& Technology Branch, National Wildlife Research Center, Carleton University, Ottawa, Ontario, Canada), Giovanni

7. Exposure to Rare Earth Elements in Animals: A Systematic Review of Biological Effects in Mammals, Fish, and Invertebrates

Pagano (Department of Chemical Sciences, Federico II Naples University, Naples, Italy), and Rahime Oral (Ege University, Faculty of Fisheries, zmir, Turkey)

Marc A. Nascarella (Environmental Toxicology Program, Massachusetts Department of Public Health, Boston, Massachusetts, USA) and Edward J. Calabrese (Department of Environmental Health Sciences, University of Massachusetts, Amherst, Massachusetts, USA)

8. Hazard Assessment and the Evaluation of Rare Earth Element Dose-Response Relationships

Franz Goecke (Laboratory of Cell Cycles of Algae, Centre Algatech, Institute of

9. Rare Earth Elements as Phosphate Binders: From Kidneys Microbiology, The Czech Academy of Sciences (CAS), Tebo, Czech Republic) and to Lakes Helmuth Goecke (Universidad de Valparaíso, Escuela Medicina, Valparaíso \& Hospital Naval A. Nef., Sección Nefrología, Servicio Medicina, Viña Del Mar, Chile)

10. Rare Earth Elements: Modulation of Calcium-Driven James Varani (Department of Pathology, University of Michigan, 1301 Catherin Rd/SPC Processes in Epithelium and Stroma

11. Rare Earth Elements Equilibria in Aqueous Media 5602, Ann Arbor, MI, USA)

Marco Trifuoggi (Federico II University of Naples, Department of Chemical Sciences, Naples, Italy), Ermanno Vasca (University of Salerno, Department of Chemistry and Biology “A. Zambelli,” Fisciano (Salerno), Italy), and Carla Manfredi (Federico II University of Naples, Department of Chemical Sciences, Naples, Italy)

Conclusion: Identifying Main Research Priorities

Index

Note. From Rare Earth Elements in Human and Environmental Health; At the Crossroads between Toxicity and Safety" edited by Giovanni Pagano. Pan Stanford Publishing Pte. Ltd. Penthouse Level, Suntec Tower 3, 8 Temasek Boulevard, Singapore 038988, Copyright 2017, 280 pp., Print ISBN: 9789814745000, eBook ISBN: 9789814745017 . Adapted with permission.

to the global use of $\mathrm{nCeO}_{2}$ as catalytic additives in diesel fuel. The limited number of publications in the literature thus far points to $\mathrm{nCeO}_{2}$ as components of diesel exhaust particulate matter (Cassee et al. 2011; 2012; Ma et al. 2014; Snow et al. 2014), thus prompting investigations on the relevance and possible health implications of diesel exhaust particulate matter following human exposure to these elements at work or in the environment. Stunted animal growth and decreased chlorophyll production are among the forms of damage to animals and plants, respectively, that have been reviewed in separate chapters $(4,6$, and 7 ; by Philippe J. Thomas, Giovanni Pagano, and Rahime Oral).

\section{Research trends on REEs}

This book builds on recent and ongoing research developments pertaining to REE, the environment, and human health, by presenting multifaceted aspects of the elements and assessing 
potential benefits in technology, agriculture, and medicine (Chapter 3). In addition, adverse health effects are reviewed in separate chapters (Chapters 2, 4, and 7). Lastly, relevant adverse effects of REEs have been appraised following the observation of severe skin fibrosis (nephrogenic systemic fibrosis) related to the use of gadolinium as a contrast agent in magnetic resonance imaging studies (Thomsen 2006; Ramalho et al. 2016), as discussed in Chapters 7 and 10 (by James Varani). Hormesis is discussed in detail in Chapter 8 (by Marc A. Nascarella and Edward J. Calabrese). REE speciation is discussed in Chapters 9 to 11 (by Franz Goecke and Helmuth Goecke, James Varani and Marco Trifuoggi, Ermanno Vasca, and Carla Manfredi), as an indispensable tool for the interpretation of REE-related hormesis and toxicity. This book will be useful in laying out some of these challenges. Other mechanistic issues related to REE distribution characteristics in the environment are discussed in this book, such as the affinities between REEs and other elements (Chapters 9 and 10). Given this duality in REE-related environmental and health issues, this book attempts to provide an updated and balanced approach to REE research and technology with an open-minded attitude.

It also provides multifaceted updates on the roles of REEs focused on different organisms and exposure routes, and raises several issues that are relevant to environmental and occupational research. The current information gaps raise a number of questions that deserve ad hoc investigations (Gambogi and Cordier 2013). Limited information is available so far on REE exposures at work, and the available literature is confined to case reports of individuals affected by respiratory tract pathologies (mainly pneumoconiosis) who show analytical evidence of REE bioaccumulation (Atwood 2012). Occupational REE exposures have been cited by workers or end-users mining or refining ores or using REEs as part of a range of industrial applications (Rim et al. 2013). An innumerable array of workers worldwide may have been exposed to REEs (at least in the order of 100,000s). To the best of my present knowledge, no epidemiologic study has been performed to date on workers who may have been exposed to REEs while performing mining or refining activities or who may have become exposed following participation in a cascade of technological activities. The presence of other chemical/physical agents in workplaces may pose major challenges in planning epidemiologic studies (Soskolne et al. 1989). Separate major examples of these phenomena include the co-occurrence of radioactive isotopes in REE-containing ores or the co-occurrence of carbon and nanoceria particulates in diesel exhaust fumes. Based on the currently available literature on occupational REE exposures, it is realistic to foresee that appropriate epidemiologic studies should provide valuable information filling the information gaps regarding potential REE-associated effects on human health, especially (yet not confined to) respiratory pathologies (Rim et al. 2013). Another research priority should be recognized in terms of evaluating and quantifying the health risks following environmental REE exposures, by extending the present information on resident populations in mining areas (Humphries 2015). Moreover, a working hypothesis might explore whether, and to what extent, other environmental REE exposures may occur. The most severe limitation of the current databases is the lack of information about long-term REE exposures, with lifelong observations that would allow the verification of effects in terms of lifespans, late onset of chronic diseases, and causes of deaths (Calabrese 2013). These, as yet unexplored, studies might provide essential and predictive information in terms of human health effects.

\section{Discussion}

\section{The importance of research on the safety of REEs}

The adverse impacts of REEs on human and environmental health raise a growing concern not only in the scientific community, but also among a number of stakeholders, potentially including students, media workers, and decision makers. The recognized and potential benefits arising from REE-related technological applications may envisage their further advantages. This book presents recent research achievements in REE-associated health effects, which have been mostly confined to journal reports on individual laboratory studies so far. It is not only an updated and balanced approach to REE research and technology, but also provides novel yet established information as stated in the title "At the Crossroads between Toxicity and Safety." It sure that this book will assist present-day and future scientists and technologists to navigate at the crossroads between REE-associated adverse and beneficial effects. Furthermore, it is anticipated that the chapter 1 will generate great reader interest and contribute to the present knowledge on potential modifiers of individual susceptibility to the health effects of REEs in terms of the prevention of occupational diseases.

Conflicts of interest Author (K-T Rim) partly participated the writing of this book (Chapter 1), but it has no potential conflict of interest to report relevant to this article.

Acknowledgments This work was supported by the Korea Occupational Safety and Health Agency (KOSHA; Ulsan, Korea), Ministry of Employment and Labor (MoEL; Sejong, Korea), and a Grant-in-Aid for chemical hazard evaluation (2012-2016). I sincerely thank Dr. Giovanni Pagano for his contribution to our book and advice for my work.

\section{References}

Atwood DA (2012) The Rare Earth Elements: Fundamentals and Applications. John Wiley \& Sons Ltd., West Sussex

Bustamante P, Miramand P (2005) Subcellular and body distributions of 17 trace elements in the variegated scallop Chlamys varia from the French coast of the Bay of Biscay. Sci Total Environ 337: 59-73

Calabrese EJ (2013) Hormetic mechanisms. Crit Rev Toxicol 43: 580-586

Carpenter D, Boutin C, Allison JE, Parsons JL, Ellis DM (2015) Uptake and effects of six rare earth elements (REEs) on selected native and crop species growing in contaminated soils. PLoS One 10: e0129936 
Cassee FR, Campbell A, Boere AJ, McLean SG, Duffin R, Krystek P, Gosens I, Miller MR (2012) The biological effects of subacute inhalation of diesel exhaust following addition of cerium oxide nanoparticles in atherosclerosis-prone mice. Environ Res 115: 1-10

Cassee,FR, van Balen EC, Singh C, Green D, Muijser H, Weinstein J, Dreher $\mathrm{K}$ (2011) Exposure, health and ecological effects review of engineered nanoscale cerium and cerium oxide associated with its use as a fuel additive. Crit Rev Toxicol 41: 213-229

Das S, Dowding JM, Klump KE, McGinnis JF, Self W, Seal S (2013) Cerium oxide nanoparticles: Applications and prospects in nanomedicine. Nanomedicine 8: 1483-1508

EU-OSHA (2013) Priorities for Occupational Safety and Health Research in Europe: 2013-2020. European Agency for Safety and Health at Work

Gambogi J, Cordier DJ (2013) Rare Earths, in Metals and minerals. U.S Geological Survey. Available from: pubs.usgs.gov/of/2013/1072/OFR20131072

Goecke F, Jerez CG, Zachleder V, Figueroa FL, Bišová K, Øezanka T, Vítová M (2015) Use of lanthanides to alleviate the effects of metal ion deficiency in Desmodesmus quadricauda (Sphaeropleales, Chlorophyta). Front Microbiol 6: 2

Gong H Jr. (1996) Uncommon causes of occupational interstitial lung diseases. Curr Opin Pulm Med 2: 405-411

He ML, Ranz D, Rambeck WA (2001) Study on the performance enhancing effect of rare earth elements in growing and finishing pigs, J Anim Physiol Anim Nutr 85: 263-270

Herrmann H, Nolde J, Berger S, Heise S (2016) Aquatic ecotoxicity of lanthanum: A review and an attempt to derive water and sediment quality criteria. Ecotoxicol Environ Saf 124: 213-238

Humphries M (2015) Rare Earth Elements: The Global Supply Chain, Congressional Research Service, Washington

Ijad Madisch J, Sören Hofmayer S, Fickenscher H (2017) ResearchGate Available from: https://www.researchgate.net/profile/Giovanni_Pagano

Izyumov A, Plaksin G (2013) Cerium: Molecular Structure, Technological Applications and Health Effects. Nova Science Publishers, New York

Jha AM, Singh AC (1995) Clastogenicity of lanthanides: Induction of chromosomal aberration in bone marrow cells of mice in vivo. Mutat Res 341: 193-197

Ma JY, Young SH, Mercer RR, Barger M, Schwegler-Berry D, Ma JK, Castranova V (2014) Interactive effects of cerium oxide and diesel exhaust nanoparticles on inducing pulmonary fibrosis. Toxicol Appl Pharmacol 278: 135-147

McDonald JW, Ghio AJ, Sheehan CE, Bernhardt PF, Roggli VL (1995) Rare earth (cerium oxide) pneumoconiosis: Analytical scanning electron microscopy and literature review. Mod Pathol 8: 859-865

Oral R, Bustamante P, Warnau M, D’Ambra A, Guida M, Pagano G (2010) Cytogenetic and developmental toxicity of cerium and lanthanum to sea urchin embryos. Chemosphere 81: 194-198

Pagano G, Aliberti F, Guida M, Oral R, Siciliano A, Trifuoggi M, Tommasi F (2015b) Human exposures to rare earth elements: State of art and research priorities. Environ Res 142: 215-220

Pagano G, Guida M, Siciliano A, Oral R, Koçbar F, Palumbo A, Castellano I,
Migliaccio O, Thomas PJ, Trifuoggi M (2016) Comparative toxicities of selected rare earth elements: Sea urchin embryogenesis and fertilization damage with redox and cytogenetic effects. Environ Res 147: 453-460

Pagano G, Guida M, Tommasi F, Oral R (2015a) Health effects and toxicity mechanisms of rare earth elements: Knowledge gaps and research prospects. Ecotoxicol Environ Saf 115C: 40-48

Pang X, Li D, Peng A (2002) Application of rare-earth elements in the agriculture of China and its environmental behavior in soil. Environ Sci Pollut Res Int 9: 143-148

Pierscionek BK, Li Y, Yasseen AA, Colhoun LM, Schachar RA, Chen W (2010) Nanoceria have no genotoxic effect on human lens epithelial cells. Nanotechnology 21: 035102

Ramalho J, Semelka RC, Ramalho M, Nunes RH, Al Obaidy M, Castillo M (2016) Gadolinium-based contrast agent accumulation and toxicity: An update. Am J Neuroradiol 37: 1192-1198

Redling K (2006) Rare Earth Elements in Agriculture with Emphasis on Animal Husbandry. Deutsche Veterinärmedizinische Gesellschaft Giessen, München

Rim KT, Koo KH, Park JS (2013) Toxicological evaluations of rare earths and their health impacts to workers: A literature review. Saf Health Work 4: $12-26$

Sabbioni E, Pietra R, Gaglione P, Vocaturo G, Colombo F, Zanoni M, Rodi F (1982) Long-term occupational risk of rare-earth pneumoconiosis. A case report as investigated by neutron activation analysis. Sci Total Environ 26: 19-32

Schubert D, Dargusch R, Raitano J, Chan SW (2006) Cerium and yttrium oxide nanoparticles are neuroprotective. Biochem Biophys Res Commun 342: 86-91

Snow SJ, McGee J, Miller DB, Bass V, Schladweiler MC et al. (2014) Inhaled diesel emissions generated with cerium oxide nanoparticle fuel additive induce adverse pulmonary and systemic effects. Toxicol Sci 142: 403417

Soskolne CL, Pagano G, Cipollaro M, Beaumont JJ, Giordano GG (1989) Epidemiologic and toxicologic evidence for chronic health effects and the underlying biologic mechanisms involved in sub-lethal exposures to acidic pollutants. Arch Environ Health 44: 180-191

Thomsen HS (2006) Nephrogenic systemic fibrosis: A serious late adverse reaction to gadodiamide. Eur Radiol 16: 2619-2621

US Environmental Protection Agency (EPA) (2012) Rare Earth Elements: A Review of Production, Processing, Recycling, and Associated Environmental Issues (EPA 600/R-12/572). Available from: http://www.epa.gov/ord

Wen K, Liang C, Wang L, Hu G, Zhou Q (2011) Combined effects of lanthanum ion and acid rain on growth, photosynthesis and chloroplast ultrastructure in soybean seedlings. Chemosphere 84: 601-608

Wong LL, McGinnis JF (2014) Nanoceria as bona fide catalytic antioxidants in medicine: What we know and what we want to know. Adv Exp Med Biol 801: 821-828

Yoon HK, Moon HS, Park SH, Song JS, Lim Y, Kohyama N (2005) Dendriform pulmonary ossification in a patient with rare earth pneumoconiosis. Thorax 60: 701-703 